Research Article

\title{
Study on Mechanical Properties of Basalt Fiber-Reinforced Concrete with High Content of Stone Powder at High Temperatures
}

\author{
Lina Xu $\mathbb{D}^{1},{ }^{1,2}$ Daohan Song $\mathbb{D}^{3},{ }^{3}$ Ning Liu $\mathbb{D}^{\circ},{ }^{3}$ and Wei Tian $\mathbb{D}^{2}$ \\ ${ }^{1}$ Key Laboratory for Comprehensive Energy Saving of Cold Regions Architecture of Ministry of Education, \\ Jilin Jianzhu University, Changchun, China \\ ${ }^{2}$ School of Transportation Science and Engineering, Jilin Jianzhu University, Changchun 130118, China \\ ${ }^{3}$ School of Civil Engineering, Jilin Jianzhu University, Changchun 130118, China \\ Correspondence should be addressed to Ning Liu; liuning86@jlju.edu.cn
}

Received 26 September 2021; Revised 18 November 2021; Accepted 25 November 2021; Published 17 December 2021

Academic Editor: Carlos R. Rambo

Copyright ( $\odot 2021$ Lina Xu et al. This is an open access article distributed under the Creative Commons Attribution License, which permits unrestricted use, distribution, and reproduction in any medium, provided the original work is properly cited.

\begin{abstract}
Concrete materials are an important part of global structure, and their fire resistance directly affects the safety of buildings and tunnels. In this study, basalt fiber was used to reinforce concrete with high content of stone powder in order to enhance its hightemperature performance. The mechanical properties and ultrasonic characteristics at different temperatures were studied using the cube compressive strength test and nonlinear ultrasonic test. The results indicated that the addition of basalt fiber in specimens improved their compressive strength; however, this strength did not continuously increase with increases in the fiber length and fiber content, and the optimal values for fiber length and fiber content were determined to be $12 \mathrm{~mm}$ and $1 \mathrm{~kg} / \mathrm{m}^{3}$ at $600^{\circ} \mathrm{C}$, respectively. With increases in temperature, the unconfined compressive strength increased first and then decreased. When the temperature was $400^{\circ} \mathrm{C}$, the unconfined compressive strength of the specimens reached their highest values and then decreased. When the temperature was $400^{\circ} \mathrm{C}$ and $600^{\circ} \mathrm{C}$, the strength of the stone powder concrete with fiber was higher than that without fiber, which shows that fiber can improve the mechanical properties of concrete at high temperatures. Based on the Box-Behnken design (BBD) method, the unconfined compressive strength response regression model of basalt fiber-reinforced concrete with high content of stone powder, which follows parameters including fiber content, fiber length, and temperature at high-temperature environments, was established, and it was found that the interaction of fiber content, fiber length, and the temperature was significant based on multifactor interaction analysis. The analysis of ultrasonic signals based on the $S$ transform showed that, with increases in temperature, the amplitudes of the acoustic response signals, the corresponding frequency spectrum, and the time-frequency spectrum were clearly reduced. At the same temperature, the amplitudes of the acoustic response signals of different concrete testing blocks did not change much and remained at the same level.
\end{abstract}

\section{Introduction}

Concrete is one of the cement products used in many parts of construction, such as buildings, bridges, tunnels, and roads. Studies show that the cement industry demands a vast amount of energy and also releases a large amount of carbon dioxide into the atmosphere-up to 13,500 tons per year, which is $7 \%$ of greenhouse gas emissions annually produced and causes additional environmental pollution $[1,2]$. Therefore, many scholars are currently devoted to the study of cement alternative materials.
It has been found that some fillers, such as limestone fines, granite dust, quartzite fines, rock dust, and recycled crushed stone powder, are good substitutes for cement and other cementitious materials [3-7]. These fillers can not only reduce the amount of cement and cementitious materials used but also have significant effects on the strength, durability, and dimensional stability of concrete [8]. In 2018, Khodabakhshian et al. found that the strength and durability of concrete containing marble waste powder tended to decline for replacement ratios over $10 \%$, but satisfactory results were obtained below that level of replacement [9]. In 
2018, Davraz et al. investigated the pozzolanic activities and efficiency factors of andesite waste powder and found that the optimum replacement rate of andesite waste powder was $10 \%$ for the C40 strength class [10]. In 2010, Aruntas et al. found that $10 \%$ of waste marble dust can be used as an additive material in cement manufacturing [11]. In addition, pumice [12], fly ash [13-15], blast furnace [16], and silica fume [17] have also produced good effects in concrete engineering. Most research has focused on the optimal mixing amounts of these fillers, but there is little research on the mechanical properties of concrete with high content of the stone powder.

In recent years, fires have frequently occurred all over the world, causing immeasurable losses. Concrete materials are an important part of global structure, and their fire resistance directly affects the safety of buildings and tunnels. When a concrete structure is exposed to fire, it is very prone to bursting, causing the concrete surface to peel off, thereby destroying the integrity of the components and deteriorating the material properties of the concrete. Because high temperatures have adverse effects on the mechanical and durability properties of concrete structures, it is important to find some solutions to improve the properties of concrete at high temperatures [18]. Some tests show that high temperatures can damage the durability of the properties of concrete; however, the addition of fibers, such as glass fiber [18], polymer fiber [19, 20], steel fiber [21, 22], basalt fiber [23], and hybrid fiber [24], has been shown to compensate for this damage. Basalt fiber is an environmentally friendly and nonhazardous bio-based material that has high tensile strength and high temperature resistance, so it has been widely used in various construction projects [25]. In 2021, Haido et al. found that the splitting tensile strength of self-compacting concrete was increased by adding $0.25 \%$ of basalt fiber [26]. In 2020 , Mohammadyan-Yasouj et al. found that basalt fiber and alginate were effective at stopping the strength reduction in cement concrete under raised temperatures [27]. In 2020, Wang et al. found that basalt fiber is beneficial to the improvement of the compressive strength of recycled concrete and that basalt fiber has a more significant effect on splitting tensile strength at elevated temperatures. The relative residual splitting tensile strength increases as the basalt fiber content increases [28]. In 2020, Zhou et al. found that the deterioration percentages of both peel and shear interface fracture toughness of basalt FRP-bonded concrete were smaller than those of aramid FRP-bonded concrete [29]. In 2016, Ren et al. found that basalt fiber was effective in improving the strength performance, deformation capacity, and energy absorption property of concrete under high temperatures [30]. This study shows that basalt fiber can improve the performance of concrete under elevated temperatures [31]. In 2020, Haido et al. proposed new models for constitutive relationships to predict the performance of BFRC under tensile and compressive stresses and to estimate its modulus of rigidity after cracking [32]. However, few studies have reported on the mechanical properties of basalt fiber-reinforced concrete with high content of stone powder at high temperatures.
This study, then, aims at investigating the mechanical properties of basalt fiber-reinforced concrete with high content of stone powder at different temperatures $\left(200^{\circ} \mathrm{C}, 400^{\circ} \mathrm{C}\right.$, and $600^{\circ} \mathrm{C}$ ) using the high-temperature test, compressive strength test, and nonlinear ultrasonic test of the cube. The influences of the fiber content, fiber length, and temperature on the mechanical properties, inflicting factors, and ultrasonic characteristics of concrete with high content of stone powder are discussed. The research path diagram is shown in Figure 1.

\section{Materials and Specimen Preparation}

2.1. Stone Powder. Stone powder produced by Jiangxi Xintao Technology Co., Ltd. (Pingxiang, China) was used in the test. The XRD test was carried out using an X-ray diffractometer (Panalytical B.V., the Netherlands) to measure the main mineral compositions of stone powder. The XRD test results are shown in Figure 2. The main mineral compositions of the stone powder used in the test were quartz, albite, K-feldspar, dolomite, clinoptilolite, and biotite. The compositions and contents of the main oxides are shown in Table 1.

2.2. Basalt Fiber. The short-cut basalt fiber was provided by the Haining Anjie Composite Materials Company (Haining, China). The mechanical and physical properties of the basalt fiber were supplied by the manufacturer and are shown in Table 2.

2.3. Cement. Portland cement produced by Changchun Yatai Co., Ltd. (Changchun, China) was used in this study. The strength grade of the cement was M32.5. Its mechanical properties are shown in Table 3, while the chemical composition of the cement is shown in Figure 3.

2.4. Aggregate. Gravel was used as the coarse aggregate, and its particle size was $5-45 \mathrm{~mm}$. Medium-sized river sand was used as the fine aggregate, and its fineness modulus and average particle size were 2.32 and $0.15-1.18 \mathrm{~mm}$, respectively, as shown in Figure 4.

2.5. Concrete Specimen Preparation. The mix ratio selection was designed according to Specification for Mix Proportion Design of Ordinary Concrete in China (JGJ 55-2011). The sand ratio was $33 \%$, and the mixing ratio of the specimens was cement: gravel: stone $:$ water $=1: 1.49: 3.02: 0.50$. The lengths of basalt fiber were $6 \mathrm{~mm}, 12 \mathrm{~mm}$, and $18 \mathrm{~mm}$, and the fiber contents were $1 \mathrm{~kg} / \mathrm{m}^{3}, 3 \mathrm{~kg} / \mathrm{m}^{3}$, and $5 \mathrm{~kg} / \mathrm{m}^{3}$, respectively. Cube specimens with the size of $150 \mathrm{~mm} \times 150 \mathrm{~mm} \times 150 \mathrm{~mm}$ were used in the test to analyze the effect of the stone powder content, in which cement was replaced by stone powder with mass ratios of $15 \%, 18 \%$, and $21 \%$, respectively. Cube specimens with the size of $100 \mathrm{~mm} \times 100 \mathrm{~mm} \times 100 \mathrm{~mm}$ were used for the high-temperature test and mechanical property test, in which cement was replaced by stone powder with a mass ratio of $18 \%$. The specimen preparation process is shown in Figure 5, and the specific steps were as follows. 


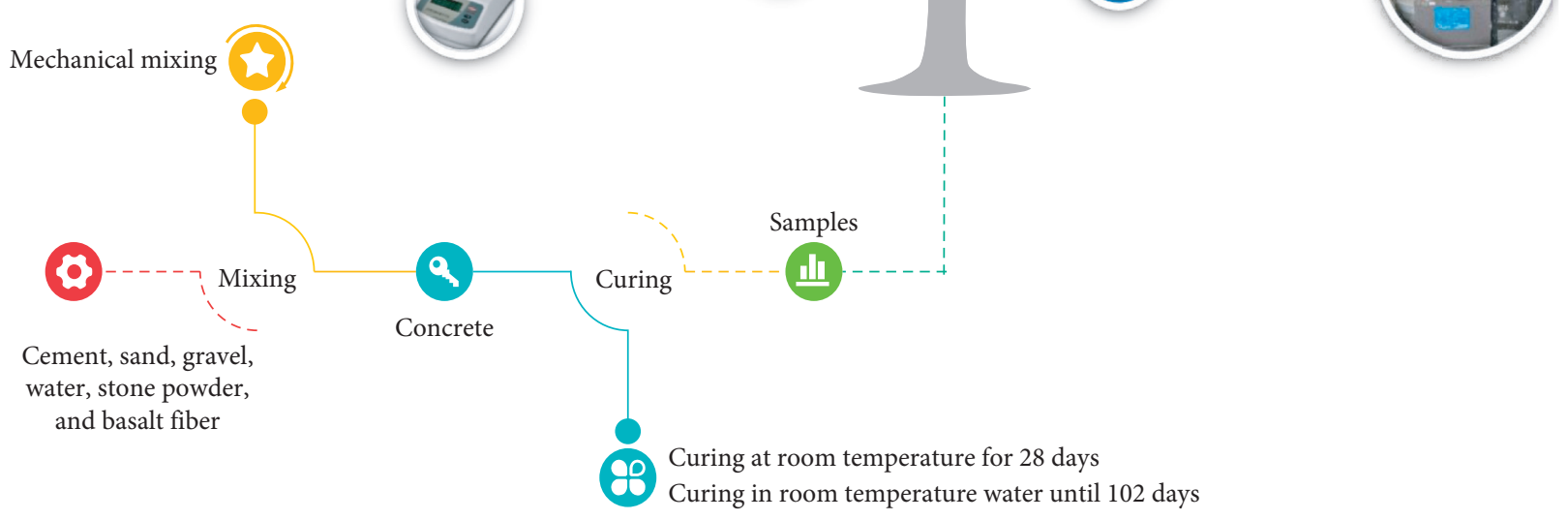

FIgURE 1: Research path diagram.

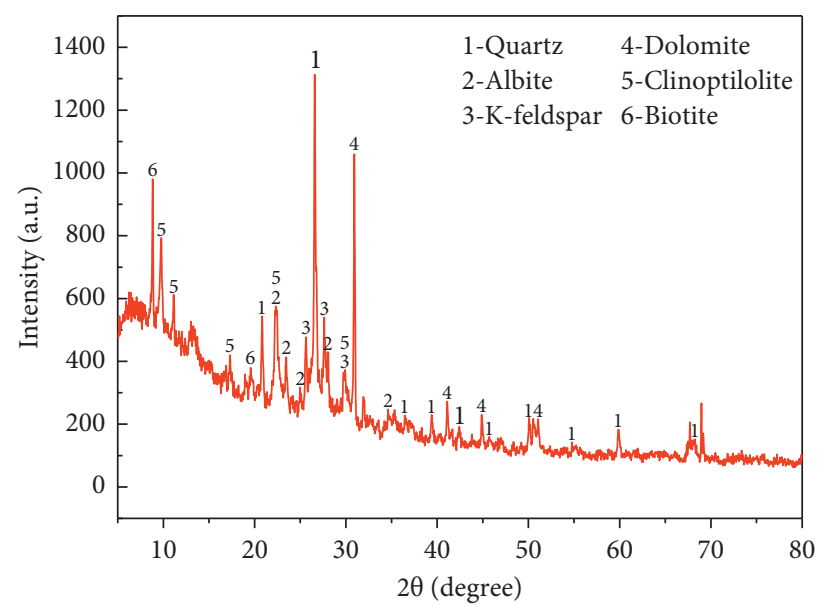

Figure 2: XRD pattern of stone powder.

TABLE 1: Composition of oxides in stone powder.

\begin{tabular}{lccccccccc}
\hline Composition & $\mathrm{SiO}_{2}$ & $\mathrm{Al}_{2} \mathrm{O}_{3}$ & $\mathrm{CaO}$ & $\mathrm{K}_{2} \mathrm{O}$ & $\mathrm{MgO}$ & $\mathrm{Fe}_{2} \mathrm{O}_{3}$ & $\mathrm{Na}_{2} \mathrm{O}$ & $\mathrm{P}_{2} \mathrm{O}_{5}$ & $\mathrm{TiO}_{2}$ \\
\hline Content (\%) & 65.703 & 12.956 & 10.366 & 3.788 & 3.554 & 1.43 & 1.274 & 0.366 & 0.252 \\
\hline
\end{tabular}

TABLE 2: Mechanical and physical properties of basalt fiber.

\begin{tabular}{lc}
\hline Parameters & Values \\
\hline Diameter $(\mu \mathrm{m})$ & $7 \sim 15$ \\
Length $(\mathrm{mm})$ & $6,12,18$ \\
Color & Golden \\
Tensile strength $(\mathrm{MPa})$ & $3000 \sim 4800$ \\
Elastic modulus $(\mathrm{GPa})$ & $91 \sim 110$ \\
Density $\left(\mathrm{g} \cdot \mathrm{cm}^{-3}\right)$ & $2.63 \sim 2.65$ \\
Thermal conductivity $\left(\mathrm{W} \cdot \mathrm{m}^{-1} \cdot \mathrm{K}^{-1}\right)$ & $0.03 \sim 0.038$ \\
Service temperature $\left({ }^{\circ} \mathrm{C}\right)$ & $-269 \sim 650$ \\
\hline
\end{tabular}


TABle 3: Mechanical properties of cement.

\begin{tabular}{lcc}
\hline & Parameters & \\
\hline Setting time $(\mathrm{min})$ & & Values \\
\hline \multirow{2}{*}{ Compressive strength $(\mathrm{MPa})$} & Initial setting time & $\geq 60$ \\
& Final setting time & $\geq 720$ \\
\hline \multirow{2}{*}{ Flexural strength $(\mathrm{MPa})$} & $3 \mathrm{~d}$ & $\geq 10$ \\
& $28 \mathrm{~d}$ & $\geq 37.5$ \\
\hline
\end{tabular}

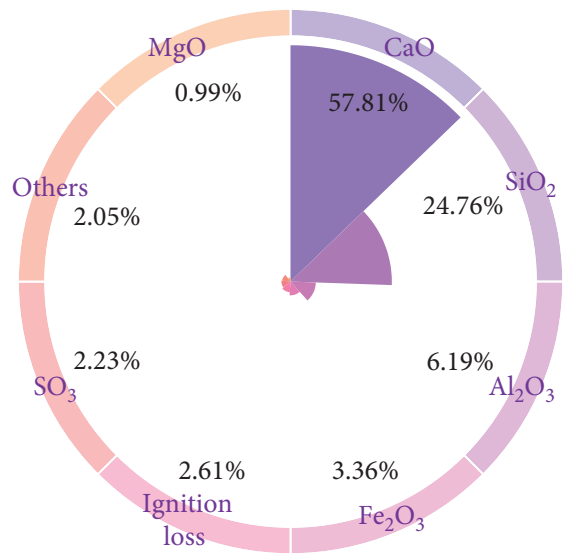

Figure 3: Chemical composition of cement.

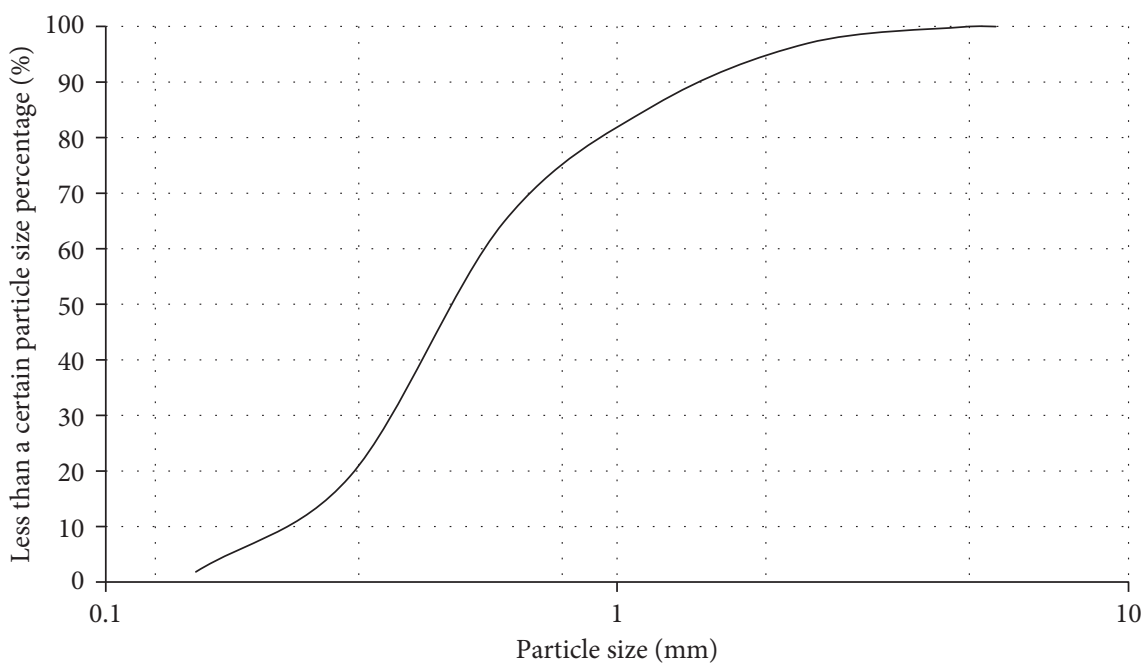

FIgURE 4: Distribution curve of river sand particle size.

Step 1: In order to mix them completely, cement, sand, stone, stone powder, and fiber were put into a push-type $280 \mathrm{~L}$ mixer for dry mixing for $5 \mathrm{~min}$. After the dry powder sufficiently settled, water was added, and the mixture was mixed for another $5 \mathrm{~min}$.

Step 2: The mixture was placed into cubical plastic molds, and layered vibration was carried out.

Step 3: The molds were placed on a vibrostand with a vibration frequency of $2,850 \mathrm{r} / \mathrm{min}$ and shaken for five minutes. Excess mortar on the surface was removed and leveled.

Step 4: The plastic molds were placed under an ambient temperature for $12 \mathrm{~h}$, and then after the specimens had attained a certain strength, they were sprayed with water and covered with a plastic film for 3 days.

Step 5: The plastic molds were then removed, and the specimens were cured at an ambient temperature for $28 \mathrm{~d}$ and then stored in a water tank at an ambient temperature for $102 \mathrm{~d}$. 
STEP 1

1) Cement, sand, gravel, stone powder and fiber were dry mixed by mixing machine for 5 minutes.

2) The water was added to the mixture and the mixture was mixed for another 5 minutes.
STEP 3

1) The molds were placed on a vibrostand with a vibration frequency of $2850 \mathrm{r} / \mathrm{min}$ for 5 minutes.

2) The excess mortar on the surface was removed and leveled.
STEP 5

1) The plastic molds were then removed, and the specimens were cured at an ambient temperature for $28 \mathrm{~d}$

2) They were stored in a water tank at an ambient temperature for $102 \mathrm{~d}$.
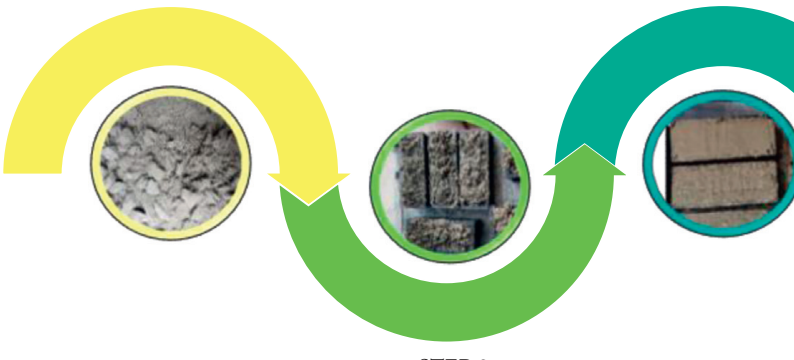

The mixture was placed into cubical plastic molds, and layered vibration was carried out.

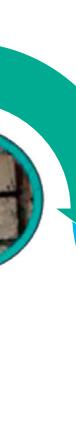

The specimens were placed at an ambient temperature for $12 \mathrm{~h}$, and the specimens were sprayed with water and cured for 3 days after the surface had a certain strength,

FIGURE 5: Specimen preparation process.

\section{Experimental Procedure and Methodology}

\subsection{Laboratory Tests}

3.1.1. High-Temperature Test. In order to prevent the specimens from bursting due to excessive moisture inside the sample, the cured specimens were placed in a dry box at $80^{\circ} \mathrm{C}$ for 4 hours and then weighed. The specimens were put into an oven for high-temperature conditioning, i.e., at $25^{\circ} \mathrm{C}$, $200^{\circ} \mathrm{C}, 400^{\circ} \mathrm{C}$, and $600^{\circ} \mathrm{C}$. The temperature-time curves for high-temperature conditioning are shown in Figure 6. The heating rate was $10^{\circ} \mathrm{C} / \mathrm{min}$. After the specimens reached the target temperatures, they were kept at a constant temperature for 2 hours, and then, they were naturally cooled to room temperature. All the specimens were weighed and tested at an age of 102 days and tested after they were cooled at a laboratory temperature of $18 \pm 22^{\circ} \mathrm{C}$.

3.1.2. Unconfined Compressive Strength Test. The unconfined compressive strength of the specimens was tested in a computer-controlled electrohydraulic servo universal testing machine according to "standard for test method of mechanical properties on ordinary concrete (GB/T 500812002)." Uniform displacement control was used in the test at a loading rate of $0.1 \mathrm{~mm} / \mathrm{s}$.

3.1.3. Nonlinear Ultrasonic Test. The nonlinear ultrasonic test is a nondestructive testing method that can be used to measure concrete damage after exposure to high temperatures. The nonlinear ultrasonic testing system consists of a signal generator, a signal amplifier, an oscilloscope, a transmitting transducer, a receiving transducer, and a computer. The test system is shown in Figure 7, and the equipment parameters are shown in Table 4 . The working principle of this system is that the electrical signal is emitted by the signal generator, which is amplified in the signal amplifier. Then, the acoustic signal is converted by the transmitting transducer and is transmitted to the concrete

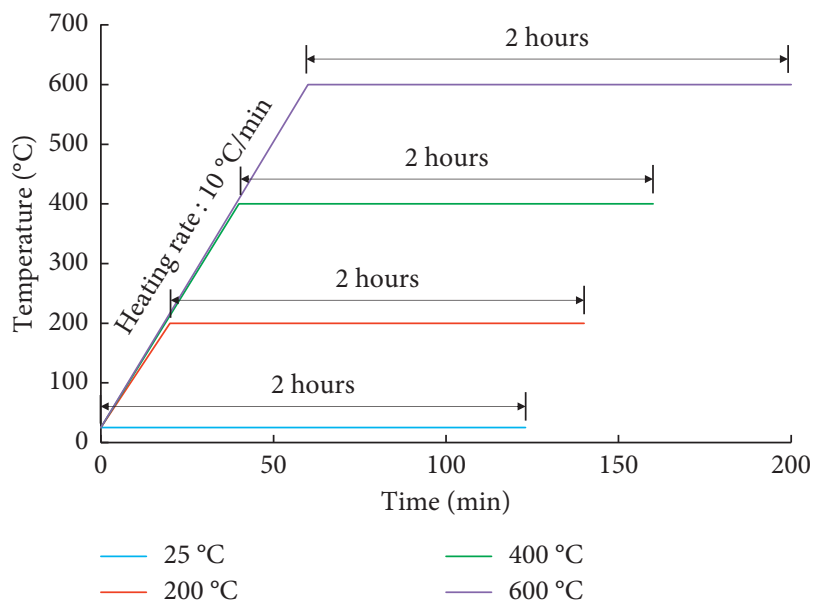

Figure 6: Temperature-time curves.

specimen. The acoustic signal is received by the receiving transducer and converted into an electrical signal. Finally, the signal is fed back to the oscilloscope.

\subsection{Methodology}

3.2.1. Response Surface Methodology. In regard to the investigation of the effects of influencing factors on the strength of concrete, several factors, such as the fiber length, fiber content, and temperature, could significantly influence the compressive strength of concrete. However, if just a single variable of the aforementioned factors is analyzed, the cross-impact of the variables is usually neglected. Response surface methodology (RSM) involves using a reasonable experimental design method and obtaining certain data through experiments. A multivariate quadratic regression equation is used to fit the functional relationship between factors and response values. The RSM is a statistical method used to find the optimal process parameters, solve multivariable problems, and perform multifactor interactive 

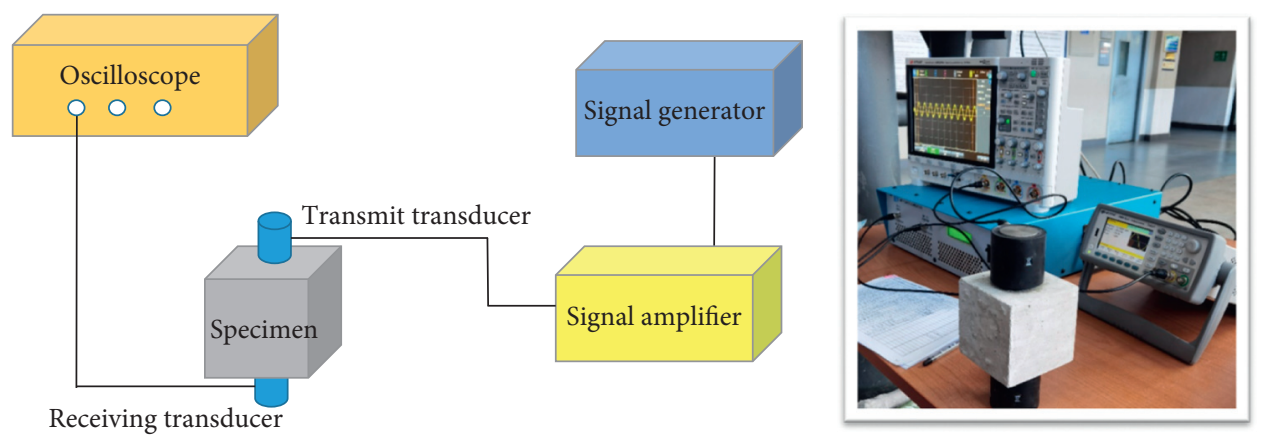

(a)

(b)

FIGURE 7: Nonlinear ultrasonic test system. (a) Schematic diagram of nonlinear ultrasonic test. (b) Field photograph of nonlinear ultrasonic test.

TABLE 4: Equipment parameters.

\begin{tabular}{lccc}
\hline Equipment & Manufacturer & Types & Parameters \\
\hline $\begin{array}{l}\text { Signal generator } \\
\text { Transmit }\end{array}$ & Keysight & $33600 \mathrm{~A}$ & $120 \mathrm{MHz}$ \\
transducer & Olympus & V1011 & $100 \mathrm{kHz}$ \\
$\begin{array}{l}\text { Receiving } \\
\text { transducer }\end{array}$ & Olympus & V1011 & $100 \mathrm{kHz}$ \\
$\begin{array}{l}\text { Signal amplifier } \\
\text { Oscilloscope }\end{array}$ & E\&I & $240 \mathrm{~L}$ & $10 \mathrm{kHz}-12 \mathrm{MHz}$ \\
\hline
\end{tabular}

analysis through regression equations. The Box-Behnken experimental design (BBD) is one of the common methods used for response surface methodology. It can evaluate the nonlinear relationship between indexes and factors.

3.2.2. Analysis Method of Acoustic Signals Based on $S$ Transform. In this study, the Box-Behnken experimental design was used to conduct an interaction analysis of the influencing factors. The unconfined compressive strength after the exposure to high temperature was used as the output variable. Basalt fiber length $X_{1}$ (unit: $\mathrm{mm}$ ), basalt fiber content $X_{2}$ (unit: $\mathrm{kg} / \mathrm{m}^{3}$ ), and temperature $X_{3}$ (unit: ${ }^{\circ} \mathrm{C}$ ) were used as input variables. The three-factor response test design was carried out. The code and level values of the test factors are shown in Table 5.

3.2.3. Test Scheme Based on BBD Method. The optimized BBD method for this experiment was determined by using Design-Expert design software, with a total of 17 groups and test sites employed. There were 12 factorial points and 5 central points, and the average unconfined compressive strength values of the three specimens were used as the response value for each group. The test scheme based on the BBD method is shown in Table 6.

3.3. Analysis Method of Acoustic Signals Based on S Transform. The analysis method of acoustic signals based on $S$ transform is one of the nonlinear ultrasonic processing methods. The Fourier transform of the entire time series contains information about the spectral components, but it cannot detect time distributions of different frequencies, so for a large class
TABLE 5: Code and level values of factors.

\begin{tabular}{lcccc}
\hline \multirow{2}{*}{ Factor } & \multirow{2}{*}{ Unit } & \multicolumn{4}{c}{ Code and level values } \\
& & -1 & 0 & 1 \\
\hline$X_{1}$ & $\mathrm{Mm}$ & 6 & 12 & 18 \\
$X_{2}$ & $\mathrm{~kg} / \mathrm{m}^{3}$ & 1 & 3 & 5 \\
$X_{3}$ & ${ }^{\circ} \mathrm{C}$ & 200 & 400 & 600 \\
\hline
\end{tabular}

TABLE 6: Test scheme based on BBD method.

\begin{tabular}{lccc}
\hline No. & $X_{1}(\mathrm{~mm})$ & $X_{2}\left(\mathrm{~kg} / \mathrm{m}^{3}\right)$ & $X_{3}\left({ }^{\circ} \mathrm{C}\right)$ \\
\hline 1 & 18.00 & 3.00 & 200.00 \\
2 & 12.00 & 3.00 & 400.00 \\
3 & 12.00 & 5.00 & 600.00 \\
4 & 18.00 & 1.00 & 400.00 \\
5 & 12.00 & 1.00 & 200.00 \\
6 & 18.00 & 5.00 & 400.00 \\
7 & 6.00 & 1.00 & 400.00 \\
8 & 18.00 & 3.00 & 600.00 \\
9 & 12.00 & 3.00 & 400.00 \\
10 & 12.00 & 3.00 & 400.00 \\
11 & 6.00 & 3.00 & 200.00 \\
12 & 12.00 & 3.00 & 400.00 \\
13 & 12.00 & 3.00 & 400.00 \\
14 & 12.00 & 5.00 & 200.00 \\
15 & 6.00 & 5.00 & 400.00 \\
16 & 12.00 & 1.00 & 600.00 \\
17 & 6.00 & 3.00 & 600.00 \\
\hline
\end{tabular}

of practical applications the Fourier transform is unsuitable until the time-frequency analysis is proposed and applied in data processing for many research fields. In order to better observe the instantaneous properties of a signal in the timefrequency domain, the $S$ transform was proposed by Stockwell and his coworkers in 1996. The $S$ transform combines the advantages of wavelet transform and shorttime Fourier transform and avoids their shortcomings, and the size of the Gaussian window scale in the $S$ transform depends on the reciprocal of the frequency and has the advantages of the multiresolution of the wavelet transform. Furthermore, there is a phase factor in the $S$ transform, which preserves the absolute phase characteristic of each frequency; this is a characteristic that the wavelet transform does not have. Meanwhile, the same as the Fourier 
transform, the $S$ transform has lossless and reversible characteristics. The one-dimensional continuous $S$ transform is defined as

$$
S(\tau, f)=\int_{-\infty}^{\infty} f(t) \frac{|f|}{\sqrt{2 \pi}} e^{\left[-f^{2}(\tau-t)^{2} / 2\right]} e^{-2 \pi f t} \mathrm{~d} t,
$$

where $S$ represents the $S$ transform of $f(t), f$ denotes the frequency, $t$ denotes the time, and $\tau$ controls the position of the Gaussian window on the time axis, which is equivalent to the shift factor in the wavelet transform.

\section{Results and Discussion}

\subsection{Unconfined Compressive Strength Test Results}

4.1.1. Influence of Stone Powder Content. The unconfined compressive strength test results of samples with different stone powder content are shown in Figure 8. It can be seen that the unconfined compressive strength of concrete was greatly affected by the addition of stone powder. In the unconfined compressive strength test, it was observed that the unconfined compressive strength of the concrete sample slowly increased with increases in the stone powder content and then significantly decreased. Compared with the specimen without stone powder, the strength of the specimen with $18 \%$ stone powder increased by $0.51 \mathrm{MPa}$, and the strength of the sample with $21 \%$ stone powder decreased by $0.97 \mathrm{MPa}$. The reason for this improvement in the unconfined compressive strength of the concrete specimen is that stone powder plays a certain filling role and improves the compactness of concrete to a certain extent, and the decrease in the unconfined compressive strength of the concrete sample can be attributed to the fact that too much cement was replaced by stone powder, resulting in a decrease in the cementitious material. By curve fitting the intensity and content, the optimal content at the maximum intensity, $18 \%$, was obtained.

4.1.2. Influence of Fiber Content. In order to study the effect of a single factor on the properties of the sample under hightemperature conditions, a temperature of $600^{\circ} \mathrm{C}$ was selected for analysis. Figure 9 illustrates the relationship between the fiber content and unconfined compressive strength at $600^{\circ} \mathrm{C}$. The results show that the strength of the specimens with fiber was higher than that of the specimens without fiber, which indicates that the addition of fiber can effectively improve the strength of specimens and their ability to resist hightemperature damage. The compressive strength of specimens with a fiber length of $12 \mathrm{~mm}$ showed an increasing trend before the fiber content reached $1 \mathrm{~kg} / \mathrm{m}^{3}$, after which the compressive strength dropped, and finally to the same level as the others. A similar performance was observed in the specimens with a fiber length of $18 \mathrm{~mm}$. The compressive strength of specimens with a fiber length of $6 \mathrm{~mm}$ increased with the increase in fiber content from 0 to $3 \mathrm{~kg} / \mathrm{m}^{3}$; however, as the fiber content increased further, the compressive strength declined. Hence, the most effective fiber content values for the compressive strength of concrete with high

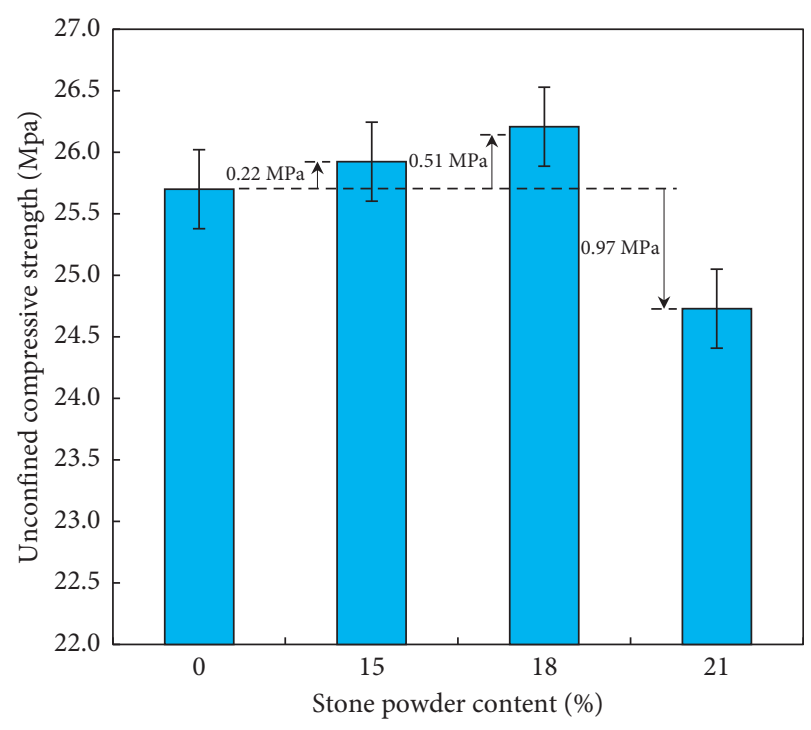

FIGURE 8: Relationship between stone powder content and unconfined compressive strength (curing time: $28 \mathrm{~d}$; specimen size: $150 \mathrm{~mm} \times 150 \mathrm{~mm} \times 150 \mathrm{~mm}$ ).

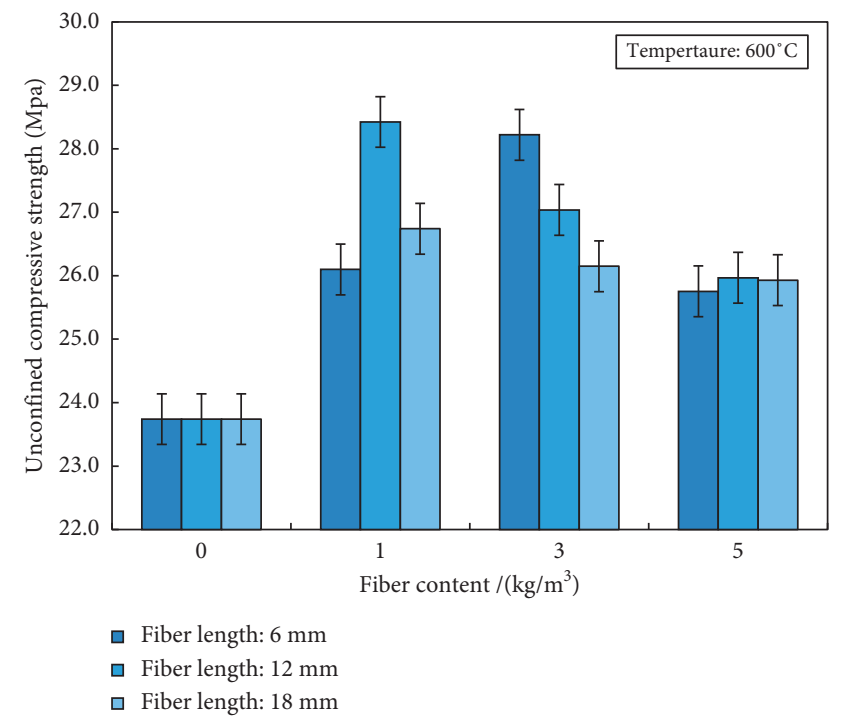

FIGURE 9: Relationship between fiber content and unconfined compressive strength (temperature: $600^{\circ} \mathrm{C}$ ).

content of stone powder at high temperatures were determined to be $1 \mathrm{~kg} / \mathrm{m}^{3}(12 \mathrm{~mm}$ and $18 \mathrm{~mm})$ and $3 \mathrm{~kg} / \mathrm{m}^{3}$ $(6 \mathrm{~mm})$. When the fiber content reached $5 \mathrm{~kg} / \mathrm{m}^{3}$, the strength of all the specimens with different lengths decreased and tended to be the same, which indicates that good effects cannot be achieved if the fiber content is too large.

4.1.3. Influence of Fiber Length. The relationship between the fiber length and unconfined compressive strength is given in Figure 10. As seen in this figure, the unconfined compressive strength at $600^{\circ} \mathrm{C}$ of the specimens with fibers of any length was higher than that of the specimens without fiber. However, as the fiber length increased, the unconfined 


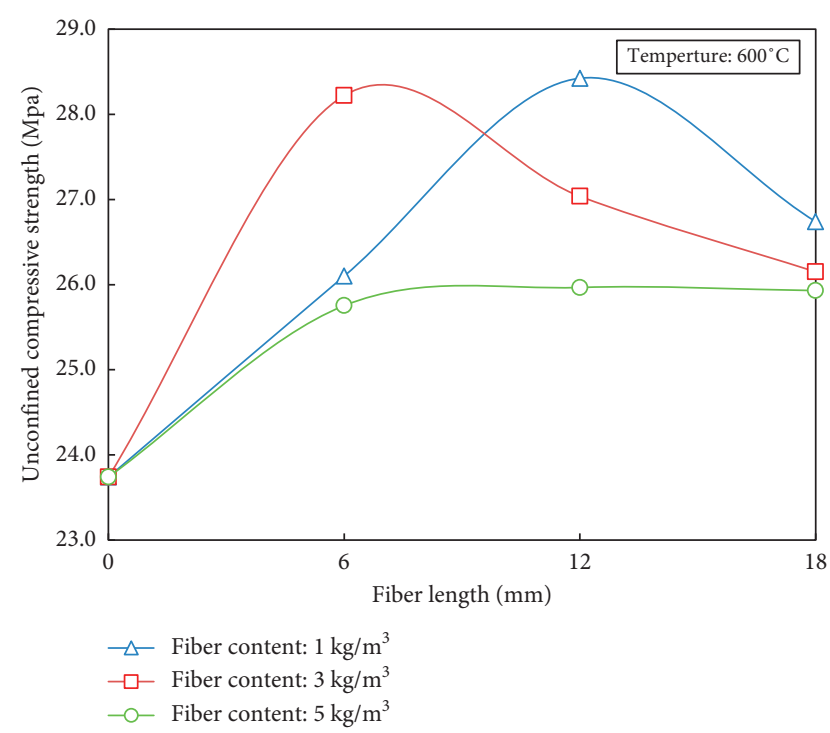

Figure 10: Relationship between fiber length and unconfined compressive strength (temperature: $600^{\circ} \mathrm{C}$ ).

compressive strength first increased and then decreased. The unconfined compressive strength of the specimens with a fiber length of $12 \mathrm{~mm}$ and content of $1 \mathrm{~kg} / \mathrm{m}^{3}$ was $20 \%$ higher than that of the specimens without fiber. The unconfined compressive strength of the specimens with a fiber length of $6 \mathrm{~mm}$ and content of $3 \mathrm{~kg} / \mathrm{m}^{3}$ was $19 \%$ higher than that of specimens without fiber. When the fiber length of $18 \mathrm{~mm}$ was added, the unconfined compressive strength of the specimen declined, which indicates that fiber lengths of this size and above do not improve the strength of concrete.

4.1.4. Influence of Temperature. Figure 11 shows the relationship between unconfined compressive strength and temperature. As can be seen, from $25^{\circ} \mathrm{C}$ to $200^{\circ} \mathrm{C}$, the strength value changed little because of the small temperature difference. The compressive strength of specimens with a fiber length of $18 \mathrm{~mm}$ and fiber content of $1 \mathrm{~kg} / \mathrm{m}^{3}$ showed an increasing trend before the temperature reached $400^{\circ} \mathrm{C}$, after which the compressive strength dropped. A similar performance could be observed in the specimens without fiber. The strength of specimens with and without fiber was increased by $30 \%$ and $19 \%$ at $400^{\circ} \mathrm{C}$, respectively. The reason for this is that part of the free water and capillary water existing inside concrete evaporates under a high-temperature environment, which forms a high-temperature steam curing environment to promote the further hydration reaction of cement, so that the strength is improved. From $400^{\circ} \mathrm{C}$ to $600^{\circ} \mathrm{C}$, the strength of specimens with and without fiber was reduced by $33 \%$ and $42 \%$, respectively. The reason for this is that the free water and capillary water are lost with increases in temperature, and microcracks and pores form inside the specimens. At the same time, the thermal expansion coefficients of the constitutive materials of the concrete are different, which leads to cracks due to the inconsistency of the thermal deformation. In addition, the crystal structure inside the material is destroyed and

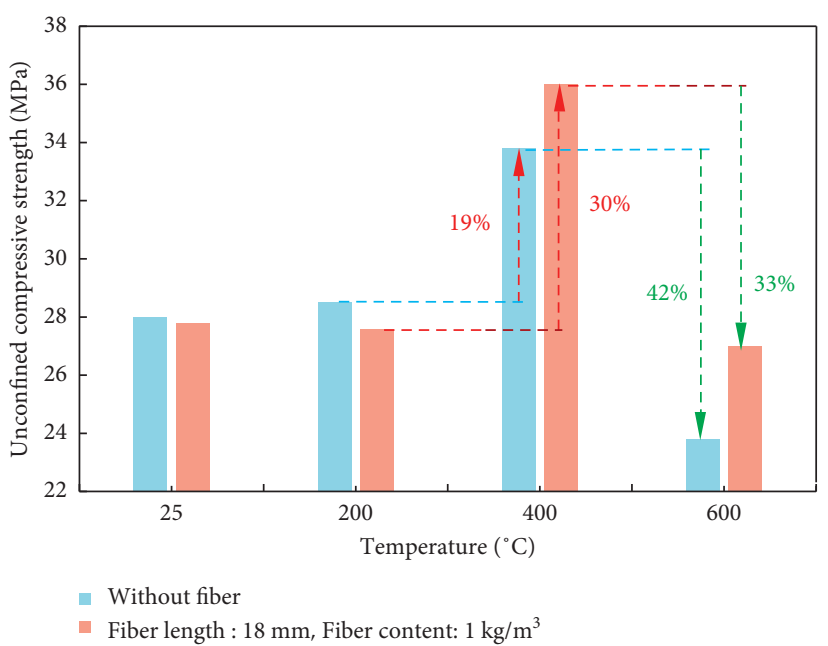

FIGURE 11: Relationship between unconfined compressive strength and temperature.

decomposed under the action of high temperatures. Therefore, when the temperature reached $600^{\circ} \mathrm{C}$, the strength of the specimens began to decline. As can be seen in this figure, the strength of the specimens with fiber decreased even more at $600^{\circ} \mathrm{C}$.

\subsection{Interaction Analysis of Influence Factors by BBD Method}

4.2.1. RSM Model Establishment. Test results based on the BBD method are shown in Table 7. A model fit summary is an evaluation method used to suggest the most suitable model in Design-Expert design software. The variance analysis of the regression model is shown in Table 8. As shown, the sequential $p$-value of the quadratic polynomial model was less than 0.0001 , and the $F$ value representing the significant difference level of the whole fitting model was 51.90 , which indicates a good fitting degree. Therefore, it is suggested that the quadratic polynomial fits the unconfined compressive strength response model.

Based on the above analysis and experimental data, the equation of the unconfined compressive strength response value is

$$
\begin{aligned}
\mathrm{US}= & -2.44+0.88 * \mathrm{FL}+2.34 * \mathrm{FC}+0.15 * T \\
& -0.0998 * \mathrm{FL} * \mathrm{FC}-1.5 e^{-4} * \mathrm{FL} * T+2.3 e^{-4} * \mathrm{FC} * T \\
& -0.025 * \mathrm{FL}^{2}-0.29 * \mathrm{FC}^{2}-1.89 e^{-4} * T^{2},
\end{aligned}
$$

where US represents unconfined compressive strength, $\mathrm{MPa}$; FL represents fiber length, $\mathrm{mm}$; FC represents fiber content, \%; $T$ represents temperature, ${ }^{\circ} \mathrm{C}$.

4.2.2. RSM Model Validation. In order to discuss the effectiveness of the quadratic polynomial regression model, the credibility of the model was analyzed, and the results are shown in Table 9. The model fitting can be analyzed by the determination coefficient $R_{2}$. The closer $R_{2}$ is to 1 , the higher the model fitting degree is. The determination coefficient $R_{2}$ of this 
TABLE 7: Test results based on BBD method.

\begin{tabular}{lcccc}
\hline No. & $X_{1}$ & $X_{2}$ & $X_{3}$ & $\begin{array}{c}\text { Unconfined compressive } \\
\text { strength }\end{array}$ \\
\hline 1 & 18.00 & 3.00 & 200.00 & 26.64 \\
2 & 12.00 & 3.00 & 400.00 & 34.34 \\
3 & 12.00 & 5.00 & 600.00 & 25.97 \\
4 & 18.00 & 1.00 & 400.00 & 35.51 \\
5 & 12.00 & 1.00 & 200.00 & 28.17 \\
6 & 18.00 & 5.00 & 400.00 & 31.64 \\
7 & 6.00 & 1.00 & 400.00 & 33.19 \\
8 & 18.00 & 3.00 & 600.00 & 26.15 \\
9 & 12.00 & 3.00 & 400.00 & 37.73 \\
10 & 12.00 & 3.00 & 400.00 & 35.03 \\
11 & 6.00 & 3.00 & 200.00 & 27.98 \\
12 & 12.00 & 3.00 & 400.00 & 36.88 \\
13 & 12.00 & 3.00 & 400.00 & 34.44 \\
14 & 12.00 & 5.00 & 200.00 & 25.3 \\
15 & 6.00 & 5.00 & 400.00 & 34.11 \\
16 & 12.00 & 1.00 & 600.00 & 28.42 \\
17 & 6.00 & 3.00 & 600.00 & 28.22 \\
\hline
\end{tabular}

TABle 8: Different statistical values form model fit summary tab.

\begin{tabular}{lcccc}
\hline Model & Sequential $p$-value & Lack of fit $p$-value & Adjusted $R$-squared & Predicted $R$-squared \\
\hline Linear & 0.9212 & 0.0133 & -0.1869 & -0.6415 \\
2FI & 0.9731 & 0.0070 & -0.5098 & -2.2805 \\
Quadratic & $<0.0001$ & 0.8168 & 0.9072 & 0.8253 \\
Cubic & 0.8168 & & 0.8684 & \\
\hline
\end{tabular}

Table 9: Credibility analysis of modified regression equation.

\begin{tabular}{lccccccccc}
\hline Parameter & Std. dev & Mean & C.V.\% & PRESS & $R^{2}$ & $R_{\text {Adj }}^{2}$ & $R_{\text {Pre }}^{2}$ & Adeq precision \\
\hline Values & 1.29 & 31.16 & 4.13 & 49.91 & 0.9594 & 0.9072 & 0.8253 & 10.069 \\
\hline
\end{tabular}

model was 0.9594, which indicates that the unconfined compressive strength response model had a good fitting. There was a good correlation between the predicted value and the measured value, and the error was small. The correction coefficient of this model was 0.9072 , indicating that $90.72 \%$ of the response value could be effectively predicted. Therefore, the design model based on the BBD method is effective.

In order to analyze the interaction of various factors, variance analysis and a significance test were performed on the quadratic polynomial model. The statistical parameters in the regression equation are shown in Table 9. The Model $F$-value of 18.38 implies that the model was significant. There was only a $0.04 \%$ chance that a "Model $F$-value" this large could have occurred due to noise. Values of "Prob $>F$ " less than 0.0500 indicate that model terms are significant. In this case, $C^{2}$ was significant model term. The $F$ value of each factor reflected its influence effect. The larger the $F$ value, the greater the influence on the response value. It can be seen from Table 10 that the quadratic term $\left(T^{2}\right)$ and fiber content (FC) had a significant influence on the response value, and the interaction between the fiber length and the fiber content (FL and FC) was significant.

Figure 12 shows the normal plot of residuals, and Figure 13 shows the relationship between the predicted and actual response values. It can be seen from Figure 12 that almost all points in the residual plot were on a straight line, which indicates that there was a normal error distribution in the test and no abnormal pattern and structure. In the graph of the relationship between the predicted and actual response values, if the point is above the diagonal, it indicates that the actual value was less than the predicted value; if the point is below the diagonal, it indicates that the actual value was greater than the predicted value; if the point happens to fall on the diagonal, it indicates that the difference between the actual value and the predicted value was relatively small. As can be seen from Figure 13, the points in the figure are on the diagonal or evenly distributed on both sides of the diagonal and close to the diagonal, indicating that the predicted value was close to the measured value and that the model has high reliability.

4.2.3. Response Surface Interaction Analysis. Based on the above analysis, the response surface model and contour map under the interaction of the unconfined compressive strength with the fiber content, fiber length, and temperature were obtained, as shown in Figures 14(a)-14(c).

As shown in Figure 14(a), there was an optimal fiber content and fiber length at each temperature, and it was optimized when the fiber content was $1 \mathrm{~kg} / \mathrm{m}^{3}$ and the fiber 
TABle 10: ANOVA of the compressive strength regression model.

\begin{tabular}{|c|c|c|c|c|c|}
\hline Source & Sum of squares & Degree of freedom & Mean square & $F$-value & $\mathrm{P}$-value \\
\hline Model & 274.12 & 9 & 30.46 & 18.38 & 0.0004 \\
\hline $\mathrm{FL}$ & 1.58 & 1 & 1.58 & 0.96 & 0.3608 \\
\hline $\mathrm{FC}$ & 8.55 & 1 & 8.55 & 5.16 & 0.0574 \\
\hline$T$ & 0.056 & 1 & 0.056 & 0.034 & 0.8592 \\
\hline FL\&FC & 5.74 & 1 & 5.74 & 3.46 & 0.1051 \\
\hline FL\&T & 0.13 & 1 & 0.13 & 0.080 & 0.7850 \\
\hline FC\&T & 0.044 & 1 & 0.044 & 0.027 & 0.8750 \\
\hline $\mathrm{FL}^{2}$ & 3.37 & 1 & 3.37 & 2.03 & 0.1969 \\
\hline $\mathrm{FC}^{2}$ & 5.83 & 1 & 5.83 & 3.52 & 0.1027 \\
\hline$T^{2}$ & 239.50 & 1 & 239.50 & 144.53 & $<0.0001$ \\
\hline Residual & 11.60 & 7 & 1.66 & - & - \\
\hline Pure error & 9.40 & 4 & 2.35 & 0.31 & - \\
\hline Cor total & 285.72 & 16 & - & - & - \\
\hline
\end{tabular}

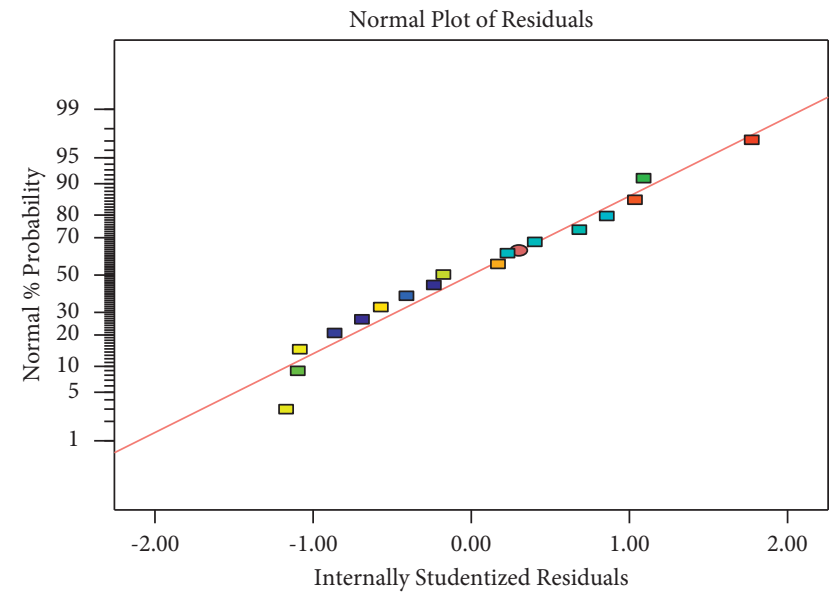

FIgURE 12: Normal plot of residuals.

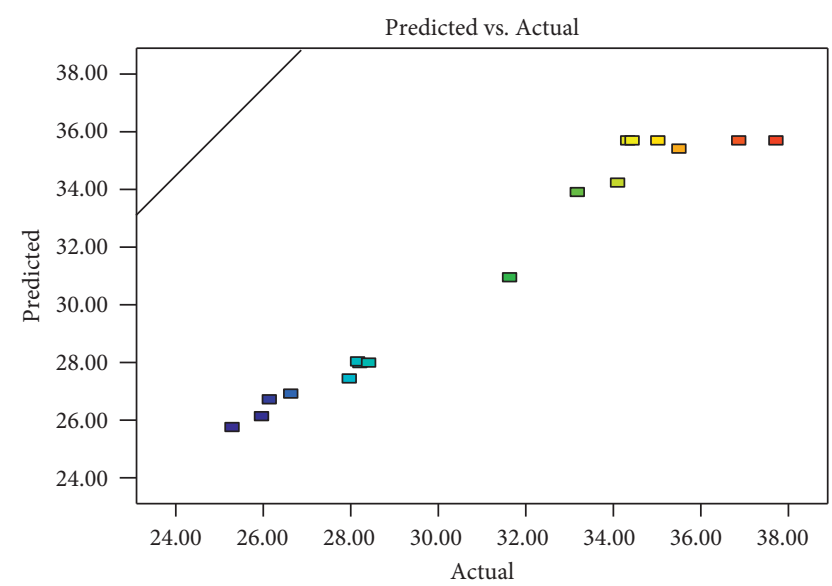

FIGURE 13: Relationship between the predicted and actual response values.

length was $18 \mathrm{~mm}$ at $400^{\circ} \mathrm{C}$. From Figures $14(\mathrm{~b})$ and $14(\mathrm{c})$, it can be seen that the unconfined compressive strength of fiber-reinforced concrete increased with the increases in temperature and that it reached its maximum at $400^{\circ} \mathrm{C}$, which followed the same pattern as that seen in Figure 11. The interaction between two factors can be reflected by the shape of the contour map. The interaction between the two factors is more significant if the contour line in the contour map is elliptical. The contour line in Figures $14(\mathrm{a})-14(\mathrm{c})$ is elliptical, which indicates that the interaction of the fiber content, fiber length, and temperature was significant for the unconfined compressive strength response index.

4.3. Acoustic Signal Analysis. Figure 15 shows the acoustic response signals, the frequency spectrum, and its timefrequency spectrum obtained using $S$ transform of the concrete without fiber and with high stone powder content added at $25^{\circ} \mathrm{C}, 200^{\circ} \mathrm{C}, 400^{\circ} \mathrm{C}$, and $600^{\circ} \mathrm{C}$, respectively. As can be observed from Figure 15(a), the acoustic response signal consists of a single-frequency signal with a time length of 0.02 seconds, a maximum amplitude of 0.04 , and a sampling rate of $100 \mathrm{kHz}$. After Fourier transform, it can be seen that the maximum amplitude of the acoustic response signal was 0.87 , the dominant frequency was $300 \mathrm{~Hz}$, and the time-frequency characteristics of the signal were correctly reflected in the time-frequency spectrum after $S$ transform. When the temperature rose to $200^{\circ} \mathrm{C}$, it can be seen in Figure 15(b) that the waveform of the acoustic response signal in the time domain did not change, but the amplitude of the acoustic response signal decreased to 0.03 . Likewise, the amplitude of the corresponding frequency spectrum and the time-frequency spectrum was also reduced. When the temperature rose to $400^{\circ} \mathrm{C}$, the amplitude of the time domain acoustic response signal was further reduced. At this time, since the amplitude of the effective signal was small enough, it can be seen in Figure 15(c) that the acoustic response signal was slightly disturbed by the background noise. At the same time, the amplitude of the corresponding frequency spectrum and time-frequency spectrum was also further reduced. When the temperature reached $600^{\circ} \mathrm{C}$, the amplitude of the acoustic response signal was further reduced, and the background noise caused serious interference to the signal. It can be seen from its frequency spectrum that after a signal with a dominant frequency of $300 \mathrm{~Hz}$ was heated at a high temperature of $600^{\circ} \mathrm{C}$, the single-frequency acoustic response signal became a full-band signal, and this change can also be clearly seen from its time-frequency spectrum. 

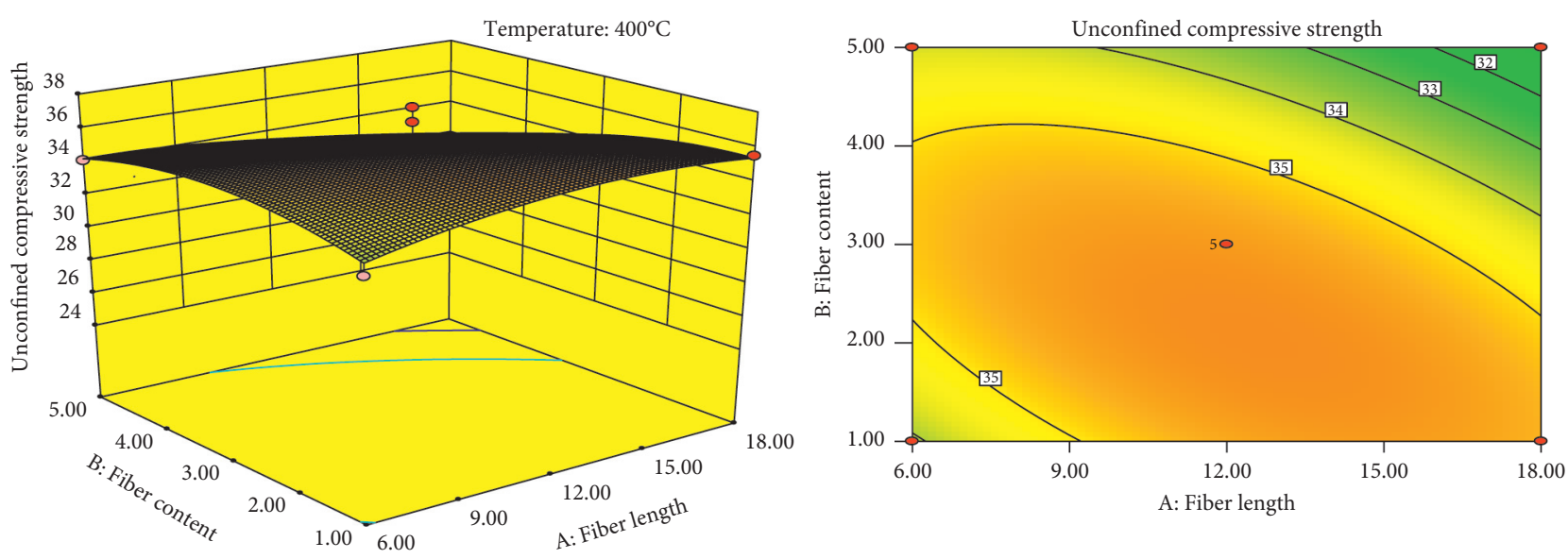

(a)
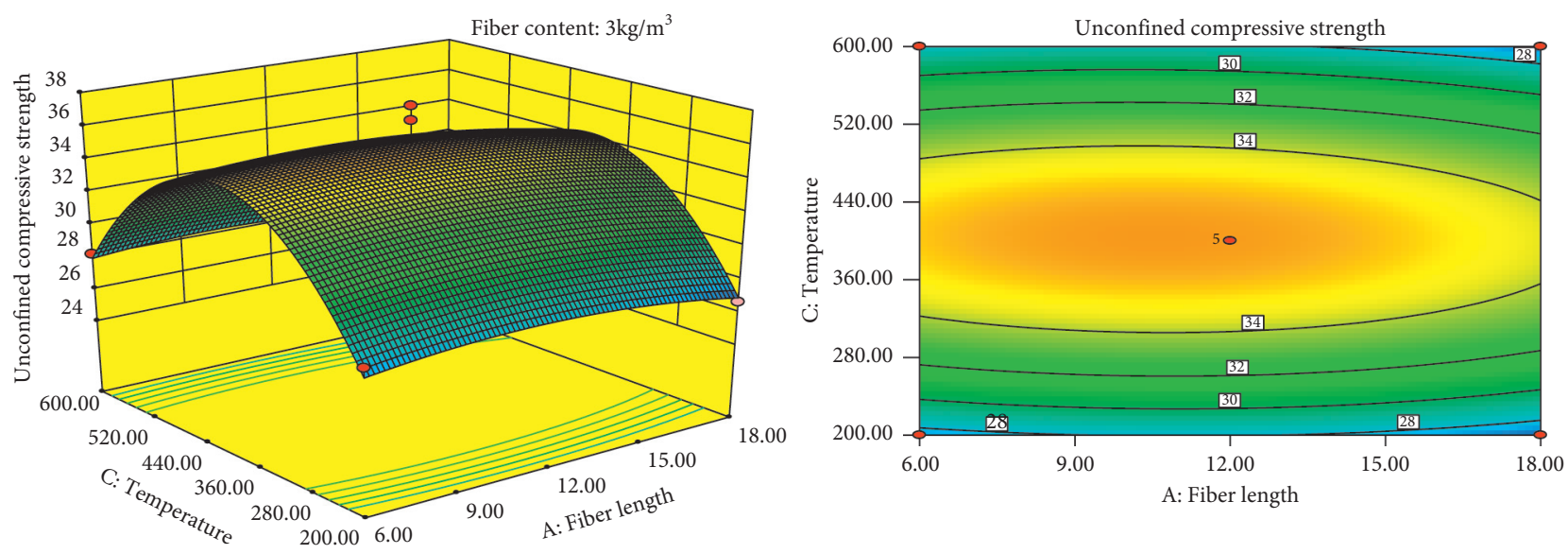

(b)
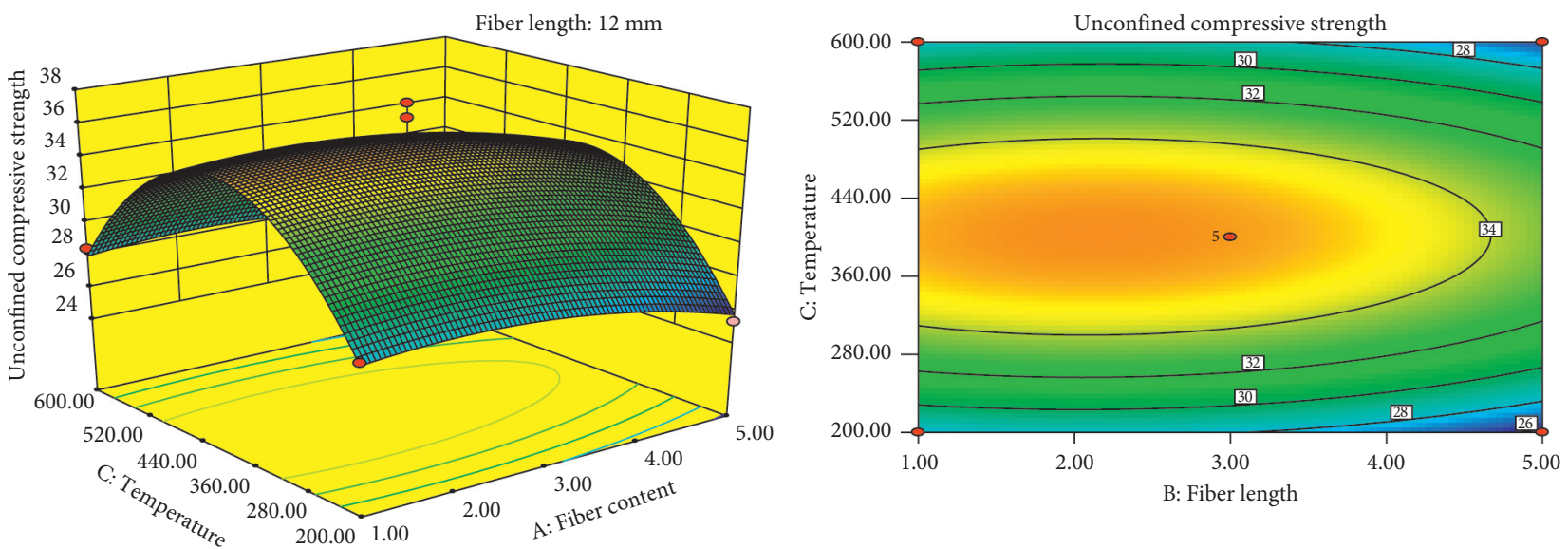

(c)

FIGURE 14: Response surface diagram and contour map of unconfined compressive strength: (a) fiber content and fiber length (400 ${ }^{\circ} \mathrm{C}$ ); (b) fiber length and temperature (fiber content: $3 \mathrm{~kg} / \mathrm{m}^{3}$ ); (c) fiber content and temperature (fiber length: $12 \mathrm{~mm}$ ).

The response signal differences in the measured concrete of fiber-free, high stone powder concrete fiber with a length of $18 \mathrm{~mm}, 3 \mathrm{~kg} / \mathrm{m}^{3}$ high stone powder content, and $6 \mathrm{~mm}$ high stone powder concrete were compared, and the content was $5 \mathrm{~kg} / \mathrm{m}^{3}$. When the temperature rose to $600^{\circ} \mathrm{C}$, the time domain acoustic response signals, the frequency spectrum, and the time-frequency spectrum of the three concrete testing blocks are shown in Figure 16. Comparing the three sets of graphs, it can be seen that although the acoustic response signal was severely disturbed by noise after the concrete was heated to $600^{\circ} \mathrm{C}$, the amplitudes of the acoustic response signals of different concrete testing blocks did not change much, remaining at the same level. The acoustic response signal of the high stone powder content concrete 

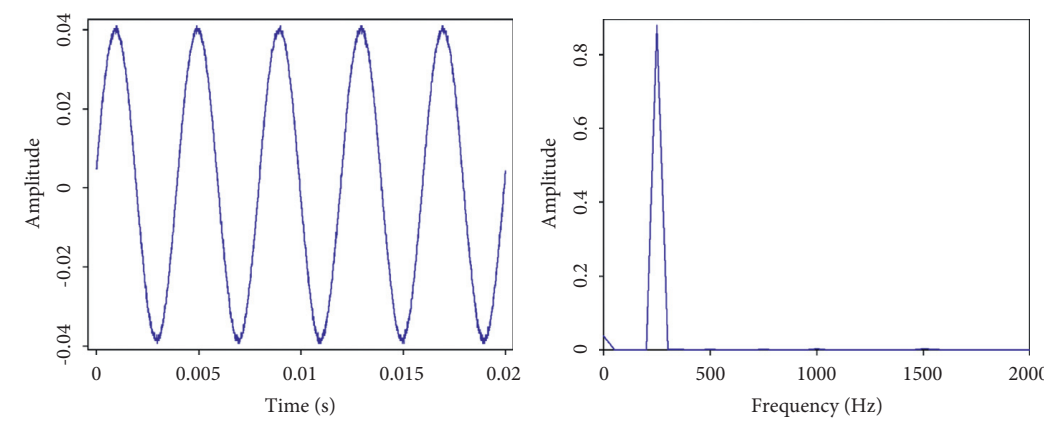

(a)
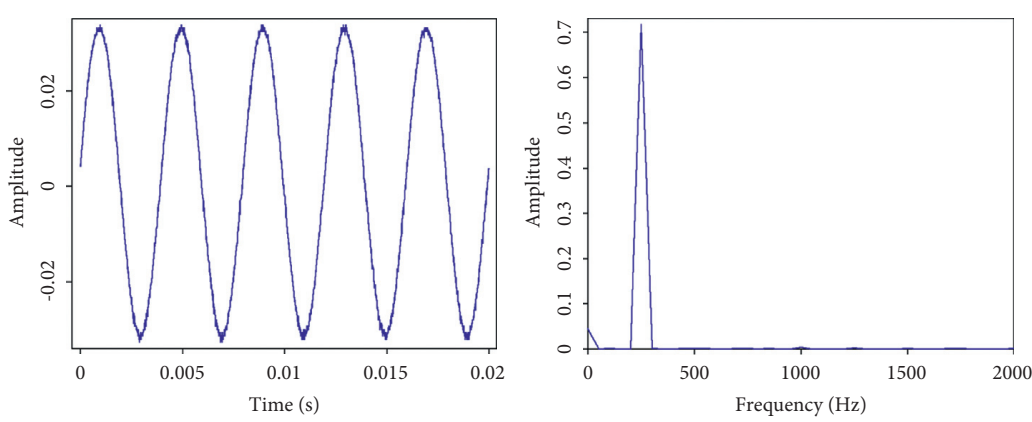

(b)
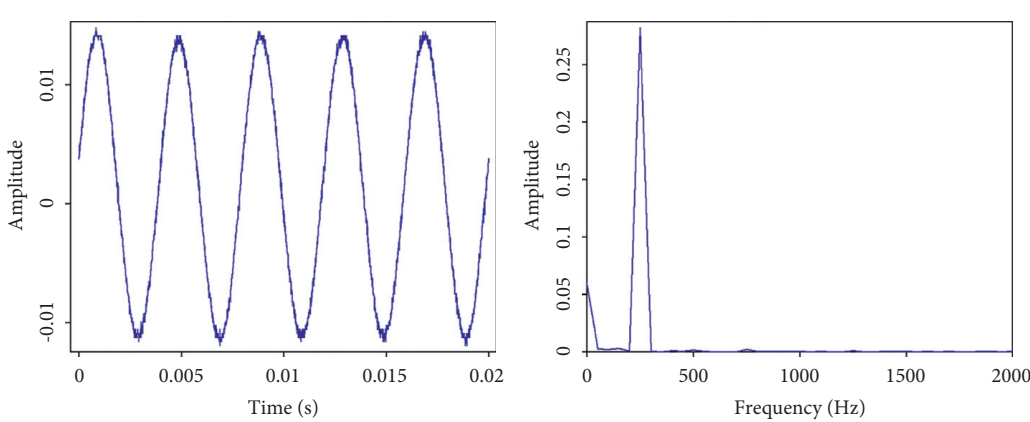

(c)
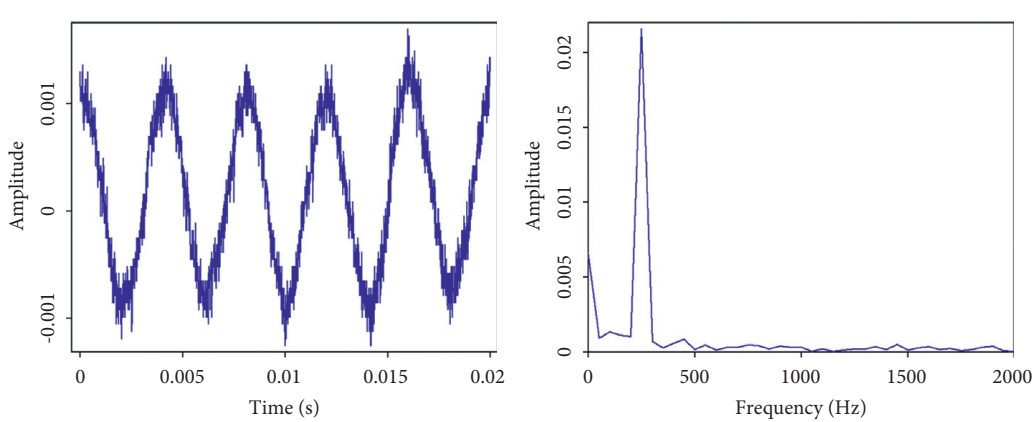

(d)
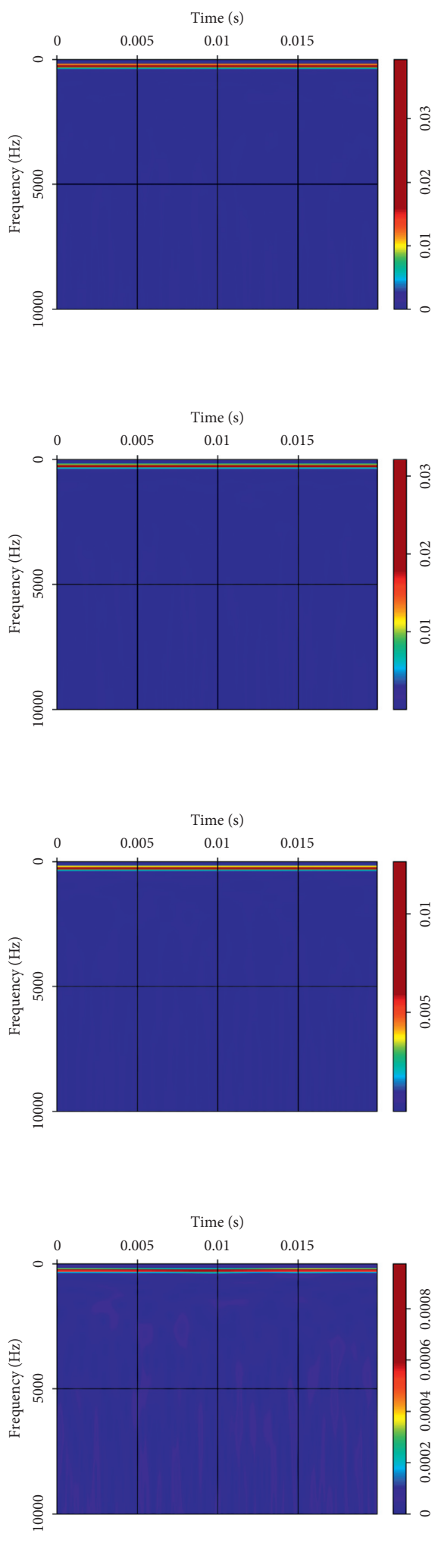

Figure 15: Acoustic response signals and processing results at different temperatures (without fiber): (a) at $25^{\circ} \mathrm{C}$; (b) at $200^{\circ} \mathrm{C}$; (c) at $400^{\circ} \mathrm{C}$; (d) at $600^{\circ} \mathrm{C}$. 

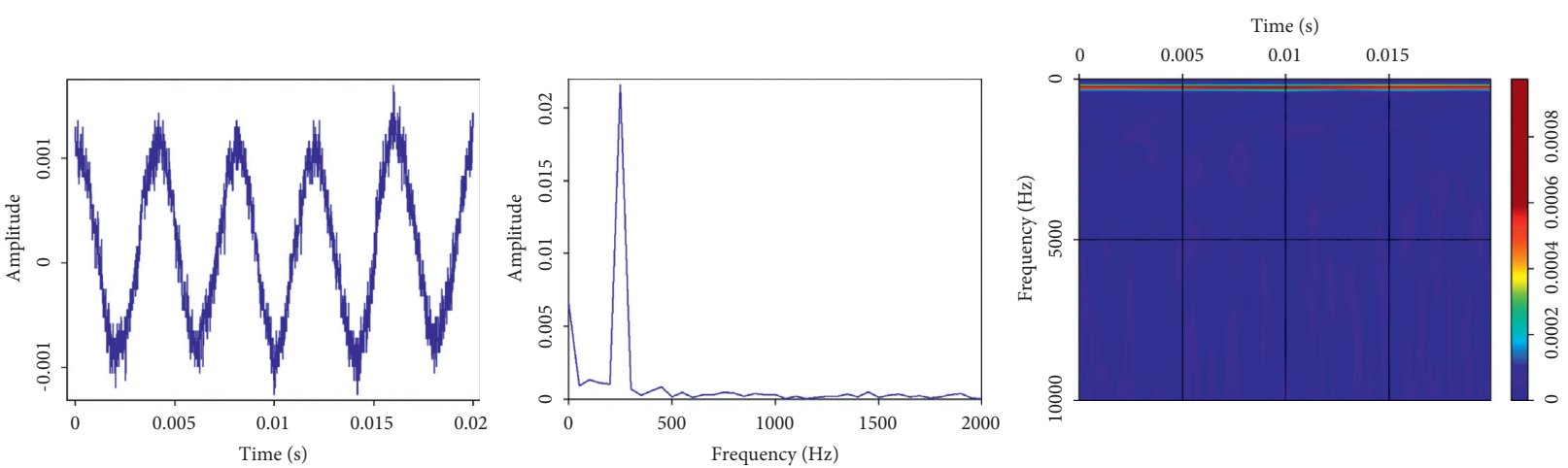

(a)
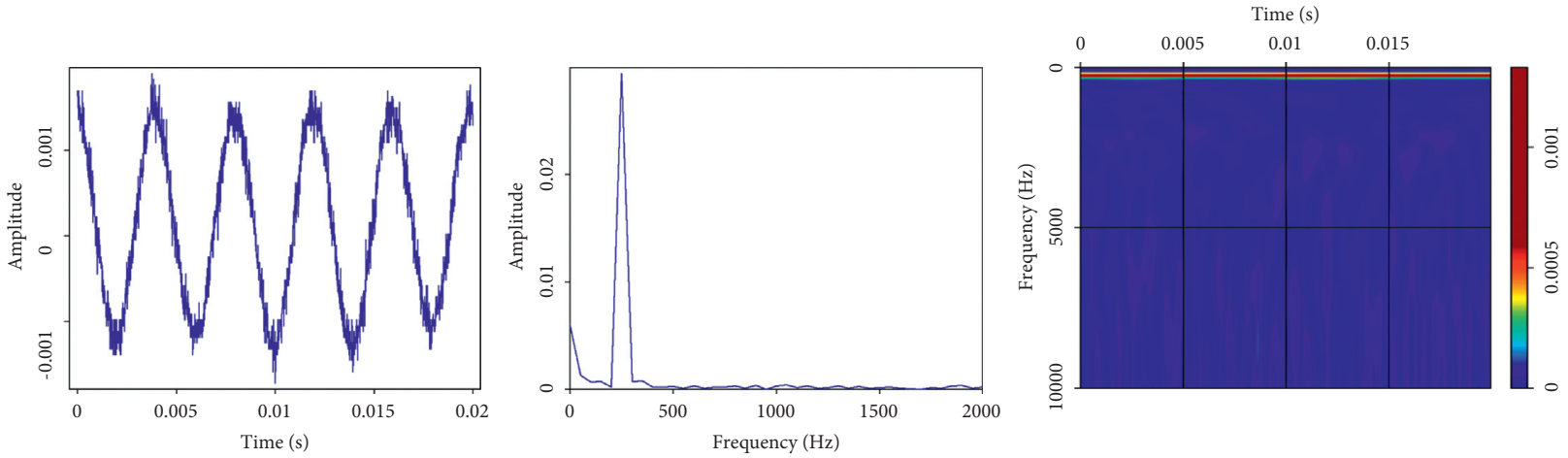

(b)
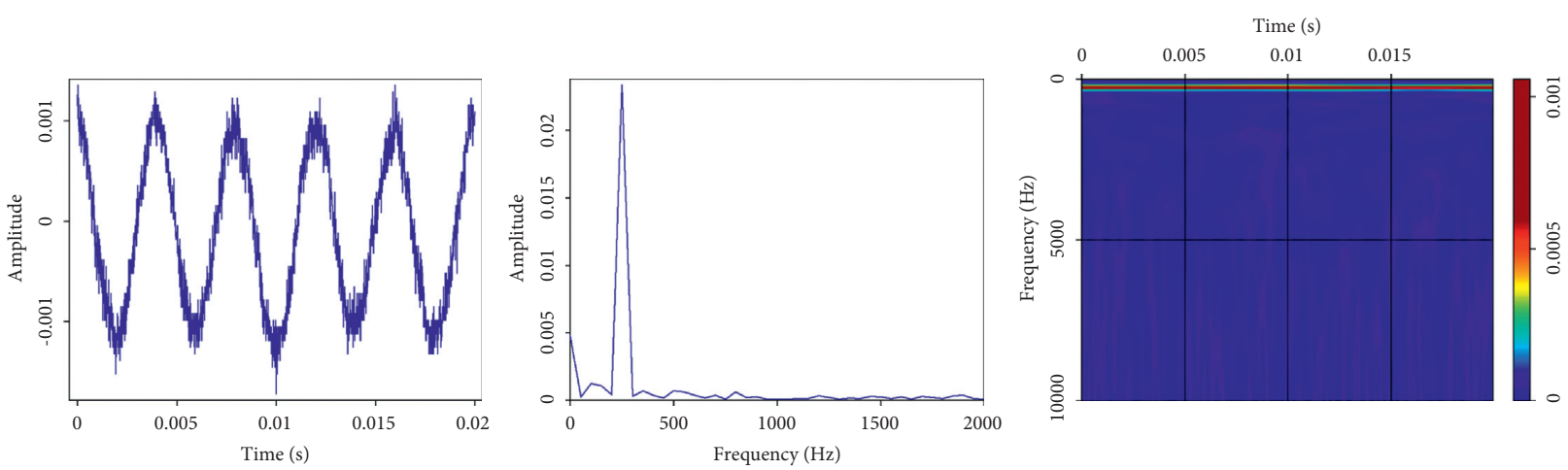

Figure 16: Acoustic response signals and processing results of concrete testing blocks (at $600^{\circ} \mathrm{C}$ ): (a) without fiber; (b) fiber length: $18 \mathrm{~mm}$ and fiber content: $3 \mathrm{~kg} / \mathrm{m}^{3}$; (c) fiber length: $6 \mathrm{~mm}$ and fiber content: $5 \mathrm{~kg} / \mathrm{m}^{3}$.

\begin{tabular}{|c|c|c|c|}
\hline No. & Without fiber & $\begin{array}{l}\text { Fiber length: } 18 \mathrm{~mm} \text { and } \\
\text { fiber content: } 3 \mathrm{~kg} / \mathrm{m}^{3}\end{array}$ & $\begin{array}{l}\text { Fiber length: } 6 \mathrm{~mm} \text { and } \\
\text { fiber content: } 5 \mathrm{~kg} / \mathrm{m}^{3}\end{array}$ \\
\hline Apparent photos & & & \\
\hline $\begin{array}{l}\text { Unconfined } \\
\text { compressive } \\
\text { strength (MPa) }\end{array}$ & 23.74 & 26.15 & 25.75 \\
\hline
\end{tabular}

Figure 17: Apparent photographs for different specimens at $600^{\circ} \mathrm{C}$. 
with a length of $18 \mathrm{~mm}$ and content of $3 \mathrm{~kg} / \mathrm{m}^{3}$ had relatively higher amplitude values in the time domain, frequency domain, and time-frequency domain. The ability of the specimens to resist cracking was enhanced by adding fibers; fewer cracks were generated under the same heating conditions, and more energy was retained when the signal passed through the specimens. The specimen with a length of $18 \mathrm{~mm}$ and content of $3 \mathrm{~kg} / \mathrm{m}^{3}$ had higher unconfined compressive strength, and there were fewer cracks on its surface at $600^{\circ} \mathrm{C}$, as shown in Figure 17 .

\section{Conclusions}

This study investigated the mechanical properties and influencing factors of basalt fiber-reinforced concrete with high content of stone powder at high temperatures using the high-temperature test, unconfined compressive strength test, and nonlinear ultrasonic test. The following main conclusions were obtained.

(1) The cement in concrete was replaced by a stone powder content of $18 \%$, which can improve the strength of concrete. In the application of concrete, replacing cement with high dosages of stone powder can realize the utilization of waste and has good ecological benefits and rapid popularization value.

(2) It was found that basalt fiber can effectively improve the cracking resistance of concrete with a high content of stone powder at high temperatures, which provides a broader space for its application at high temperatures.

(3) The unconfined compressive strength of concrete was found to increase first and then decrease with increases in the fiber content, fiber length, and temperature. It was found that the interaction between $T^{2}$ and fiber content, and the interaction between fiber length and fiber content were significant using interactive analysis of the influencing factors based on the BBD method.

(4) It was found that as the temperature gradually increased, the amplitude of the single-frequency acoustic response signal in the time domain, the frequency domain, and the signal-to-noise ratio of the signal significantly decreased. The addition of fiber had a certain delaying effect on the crack propagation of concrete at high temperatures, so that fewer cracks were generated under the same heating conditions, and more energy was retained when the acoustic signal passed through the specimen.

\section{Data Availability}

The data used to support the findings of this study are available from the corresponding author upon request.

\section{Conflicts of Interest}

The authors declare that there are no conflicts of interest regarding the publication of this paper.

\section{Acknowledgments}

The authors gratefully acknowledge the experiment and the assistance of the Key Laboratory for Comprehensive Energy Saving of Cold Regions Architecture of Ministry of Education, Jilin Jianzhu University. The research was supported by the National Natural Science Foundation of China (project no. 52008185).

\section{References}

[1] V. M. Malhotra, "Introduction: sustainable development and concrete technology," Concrete International, vol. 24, no. 22, 2022.

[2] S. B. Abdellahi and S. M. Hejazi, "Effect of glass and polypropylene fibers in cementitious composites containing waste stone powder," Journal of Industrial Textiles, vol. 45, no. 1 , pp. 152-168, 2015.

[3] D. Vaičiukynienè, V. Vaitkevičius, A. Kantautas, A. Kartovickis, and Ž. Rudžionis, "Blended cements produced with synthetic zeolite made from industrial by-product," Materials Science-Medziagotyra, vol. 21, no. 1, pp. 126-142, 2015.

[4] A. M. Rashad, "Recycled cathode ray tube and liquid crystal display glass as fine aggregate replacement in cementitious materials," Construction and Building Materials, vol. 93, pp. 1236-1248, 2015.

[5] B. Qi, J. Gao, F. Chen, and D. Shen, "Chloride penetration into recycled aggregate concrete subjected to wetting-drying cycles and flexural loading," Construction and Building Materials, vol. 174, pp. 130-137, 2018.

[6] J. Li, Q. Yu, J. Wei, and T. Zhang, "Structural characteristics and hydration kinetics of modified steel slag," Cement and Concrete Research, vol. 41, no. 3, pp. 324-329, 2011.

[7] T.-H. Song, S.-H. Lee, and B. Kim, "Recycling of crushed stone powder as a partial replacement for silica powder in extruded cement panels," Construction and Building Materials, vol. 52, pp. 105-115, 2014.

[8] L. G. Li, Y. M. Wang, Y. P. Tan, A. K. H. Kwan, and L. J. Li, "Adding granite dust as paste replacement to improve durability and dimensional stability of mortar," Powder Technology, vol. 333, pp. 269-276, 2018.

[9] A. Khodabakhshian, M. Ghalehnovi, J. de Brito, and E. Asadi Shamsabadi, "Durability performance of structural concrete containing silica fume and marble industry waste powder," Journal of Cleaner Production, vol. 170, pp. 42-60, 2018.

[10] M. Davraz, H. Ceylan, İ. B. Topçu, and T. Uygunoğlu, "Pozzolanic effect of andesite waste powder on mechanical properties of high strength concrete," Construction and Building Materials, vol. 165, pp. 494-503, 2018.

[11] H. Y. Aruntaş, M. Gürü, M. Dayı, and İ. Tekin, "Utilization of waste marble dust as an additive in cement production," Materials and Design, vol. 31, pp. 4039-4042, 2010.

[12] K. M. A. Hossain, "Blended cement using volcanic ash and pumice," Cement and Concrete Research, vol. 33, no. 10, pp. 1601-1605, 2003.

[13] P. Chindaprasirt, C. Jaturapitakkul, and T. Sinsiri, "Effect of fly ash fineness on compressive strength and pore size of blended cement paste," Cement and Concrete Composites, vol. 27, no. 4, pp. 425-428, 2005.

[14] W. Chalee, P. Ausapanit, and C. Jaturapitakkul, "Utilization of fly ash concrete in marine environment for long term design life analysis," Materials \& Design, vol. 31, no. 3, pp. 1242-1249, 2010. 
[15] A. Demirbaş and A. Aslan, "Evaluation of lignite combustion residues as cement additives," Cement and Concrete Research, vol. 29, no. 7, pp. 983-987, 1999.

[16] K. Erdogdu, M. Tokyay, and P. Türker, "Comparison of intergrinding and separate grinding for the production of natural pozzolan and GBFS-incorporated blended cements," Cement and Concrete Research, vol. 29, no. 5, pp. 743-746, 1999.

[17] Ö. Eren, K. Marar, and T. Çelik, "Effects of silica fume and steel fibers on some mechanical properties of high-strength fiber-reinforced concrete," Journal of Testing and Evaluation, vol. 27 , no. 6, pp. 380-387, 1999.

[18] M. A. Moghadam and R. A. Izadifard, "Effects of steel and glass fibers on mechanical and durability properties of concrete exposed to high temperatures," Fire Safety Journal, vol. 11, Article ID 102978, 2020.

[19] D. Zhang, Y. Zhang, A. Dasari, K. H. Tan, and Y. H. Weng, "Effect of spatial distribution of polymer fibers on preventing spalling of UHPC at high temperatures," Cement and Concrete Research, vol. 140, Article ID 106281, 2012.

[20] M. Abdul-Rahman, A. A. Al-Attar, H. M. Hamada, and B. Tayeh, "Microstructure and structural analysis of polypropylene fibre reinforced reactive powder concrete beams exposed to elevated temperature," Journal of Building Engineering, vol. 29, Article ID 101167, 2020.

[21] H. Li, X. Hao, Y. Liu, and Q. Wang, "Thermal effects of steelfibre-reinforced reactive powder concrete at elevated temperatures," Magazine of Concrete Research, vol. 73, no. 3, pp. 109-120, 2021.

[22] M. Colombo, M. Di Prisco, and R. Felicetti, "Mechanical properties of steel fibre reinforced concrete exposed at high temperatures," Materials and Structures, vol. 43, no. 4, pp. 475-491, 2010.

[23] T. Bhat, V. Chevali, X. Liu, S. Feih, and A. P. Mouritz, "Fire structural resistance of basalt fibre composite," Composites Part A: Applied Science and Manufacturing, vol. 71, pp. 107-115, 2015.

[24] H. Y. Wu, X. S. Lin, and A. N. Zhou, "A review of mechanical properties of fibre reinforced concrete at elevated temperatures," Cement and Concrete Research, vol. 135, Article ID 106117, 2020.

[25] V. Fiore, T. Scalici, G. Di Bella, and A. Valenza, "A review on basalt fibre and its composites," Composites Part B: Engineering, vol. 74, pp. 74-94, 2015.

[26] J. H. Haido, B. A. Tayeh, S. S. Majeed, and M. Karpuzcu, "Effect of high temperature on the mechanical properties of basalt fibre self-compacting concrete as an overlay material," Construction and Building Materials, vol. 268, no. 25 January, Article ID 121725, 2021.

[27] S. E. Mohammadyan-Yasouj, H. A. Ahangar, N. A. Oskoei, H. Shokravi, S. S. R. Koloor, and M. Petrů, "Thermal performance of alginate concrete reinforced with basalt fiber," Crystals, vol. 10, no. 9, Article ID 779, 2020.

[28] Y. G. Wang, S. P. Li, P. Hughes, and Y. H. Fan, "Mechanical properties and microstructure of basalt fiber and nano-silica reinforced recycled concrete after exposure to elevated temperatures," Construction and Building Materials, vol. 247, Article ID 118561, 2020.

[29] A. Zhou, Q. W. Qiu, C. L. Chou, and D. Lau, "Interfacial performance of aramid, basalt and carbon fiber reinforced polymer bonded concrete exposed to high temperature," Composites Part A: Applied Science and Manufacturing, vol. 131, Article ID 105802, 2020.

[30] W. Ren, J. Xu, and H. Su, "Dynamic compressive behavior of basalt fiber reinforced concrete after exposure to elevated temperatures," Fire and Materials, vol. 40, no. 5, pp. 738-755, 2015.

[31] A. Khaloo, M. H. Mobini, and P. Hosseini, "Influence of different types of nano-SiO2 particles on properties of highperformance concrete," Construction and Building Materials, vol. 113, pp. 188-201, 2016.

[32] J. H. Haido, "Flexural behavior of basalt fiber reinforced concrete beams: finite element simulation with new constitutive relationships," Structure, vol. 27, pp. 1876-1889, 2020. 